\title{
Breeding population dynamics and habitat transition of Saunders's Gull Larus saundersi in Yancheng National Nature Reserve, China
}

\author{
H. X. JIANG, Y. Q. HOU, G. Z. CHU, F. W. QIAN, H. WANG, G. G. ZHANG and \\ G. M. ZHENG
}

\begin{abstract}
Summary
Saunders's Gull Larus saundersi is a breeding endemic of Common Seepweed Suaeda glauca habitats on the east coast of China and south-west coast of South Korea. Much of this habitat has been lost and degraded due to human land use and expansion of the introduced Smooth Cordgrass Spartina alterniflora. Yancheng National Nature Reserve (NNR) is one of three breeding and wintering areas in China. We used satellite images from 1992 to 2007 and visual interpretation combined with ground truthing to classify the land cover and quantify changes in land use and land cover (LULC) in areas of Yancheng NNR used by Saunders's Gull. The Common Seepweed habitat, in which this species nests, decreased in area by $79.1 \%$ (27,358 ha) over 15 years, predominantly as a result of conversion to aquaculture ponds (18,929 ha), and is now centred in the south-east of Yancheng NNR. The total population size of Saunders's Gull was maintained at over 900 individuals from 1999 to 2006 in Yancheng NNR, but was only 575 in 2007, and the number of breeding sites decreased from eight in 1992 and 1994 to a single site in 2000-2006 and two sites in 2007. From 1999 to 2007, the breeding population in the core area of Yancheng NNR accounted for $94.93 \%$ of the total population, and its nest-site spatial turnover rate was $0.84 \pm 0.08$ ( $n=7$ years), but it tended to decrease by about $40 \%$ in 2007 because of degradation of the Common Seepweed community. The conversion of Common Seepweed habitats to other habitat types and expansion of introduced Smooth Cordgrass were the major and direct reasons for the loss and degradation of breeding habitats of Saunders's Gull. Smooth Cordgrass habitats increased in area by $321.9 \%$ ( 11,057 ha) during this period and centred on the east, gradually occupying the mudflats, except the beach from Liangduo River to the south of Yancheng NNR, where potential breeding sites for the Saunders's Gull could be located. We discuss the implications of our results for the conservation this species and management of its habitats.
\end{abstract}

\section{Introduction}

Saunders's Gull Larus saundersi is recognized as 'Vulnerable' by IUCN (2008) and Birdlife International (2008), and is also listed as vulnerable in China, but it is not nationally protected due to a lack of available information (Zheng and Wang 1998). Its status and distribution have been a mystery for more than a century since its initial description (Swinhoe 1871). Following the proposal by Melville (1987), studies on Saunders's Gull were given more attention by ornithologists around the world. The current world population estimate is a minimum of 14,400 birds, which is more than $70 \%$ higher than the mid-point of the estimated range $(7,100-9,600)$ by Wetlands International (2006). However the apparent population increase is almost certainly due to increased survey effort. It is likely that the population is continuing to decline, given the 
significant threats to habitats and high human disturbance levels occurring across the species's range (Cao et al. 2008).

Saunders's Gull is restricted to Common Seepweed Suaeda glauca habitats for breeding on the east coast of China and South Korea, many of which have been lost and degraded due to human land use (Shi et al. 1988, Huang 1994, Moores 2002). Yancheng National Nature Reserve (Yancheng NNR) is one of three major breeding and wintering areas in China (Hou et al. 2000). It consists of coastal wetlands across five counties in Jiangsu Province. In recent years, some tidal marshes have been converted to aquaculture ponds, salt pans, agriculture, industrial development and other land use types. Meanwhile, since the introduction of the alien Smooth Cordgrass Spartina alterniflora into Yancheng coastal wetland in 1982 (Zhong et al. 1985), the plant has expanded into the open mudflats and occupied the periphery of the Common Seepweed community from Sheyang River to Liangduo River (Liu et al. 2009a). This has seriously affected conditions for breeding, wintering and migratory waterbirds including Red-crowned Cranes Grus japonensis, Black-faced Spoonbill Platalea minor, ducks and waders (Nanjing Environment Sciences Institute et al. 2005).

In this paper, we measure changes in habitats of Yancheng coastal wetlands, especially habitats suitable for breeding Saunders's Gulls, through interpretation of satellite images from six different years, from the establishment of the National Nature Reserve in 1992 to 2007. Combined with ground survey data on the size and distribution of the population and nests, we analysed the actual and potential impact of changes in breeding habitat on the breeding population size and distribution, as well as that of nest-sites. Finally, we also put forward some measures for species conservation and habitat management.

\section{Study area}

Yancheng NNR (Figure 1 ) is located in the centre of the east coast of China, between $32^{\circ} 38^{\prime} 03^{\prime}$ and $34^{\circ} 30^{\prime} 08^{\prime} \mathrm{N}, 119^{\circ} 51^{\prime} 25^{\prime}$ and $121^{\circ} 05^{\prime} 47^{\prime} \mathrm{E}$ (the former reserve ranged between $32^{\circ} 34$ and $34^{\circ} 3 \hat{1} \mathrm{~N}, 119^{\circ} 4^{\prime}$ and $\left.121^{\circ} 1 \xi^{\prime} \mathrm{E}\right)$. The major objective of the reserve is to protect the Red-crowned Crane and other bird species as well as their habitats. It was approved as a National Nature Reserve by the China State Council and internationally recognised as a Biosphere Reserve by UNESCO in 1992 (Han and Gretchen 1995). Due to the accretion of mudflats and anthropogenic impacts, the functional zones were adjusted and approved by China's State Council in early 2007. The current reserve area is 284,179 ha, a decrease of 169,321 ha in comparison with the former reserve (Nanjing Environment Sciences Institute et al. 2005).

The boundaries of the study area followed the former reserve boundaries except that the eastern boundary is in accordance with that of the current reserve. The area of the study area is 579,136 ha (Figure 1).

\section{Methods}

\section{Field methods}

Saunders's Gulls spend the summer from March to September in Yancheng NNR. In our study, the number and distribution of Saunders's Gulls in Yancheng NNR was surveyed in early June of each year when they are in the stable part of the breeding cycle. The gulls were counted by one person standing on a high point while the other survey members went into nesting areas. As this is a colonial nesting species ( $\mathrm{Du}$ 1994), we searched thoroughly for nests in each Common Seepweed habitat between April and July 1999-2007. Due to the occurrence of avian influenza, field work was not conducted in 2004. All nests were recorded using a GPS and marked I $\mathrm{m}$ to the south with a surveyor's flag rolled up and pushed into the ground leaving $4-5 \mathrm{~cm}$ of flag exposed to monitor productivity and also to avoid duplicate recording of nest sites. 


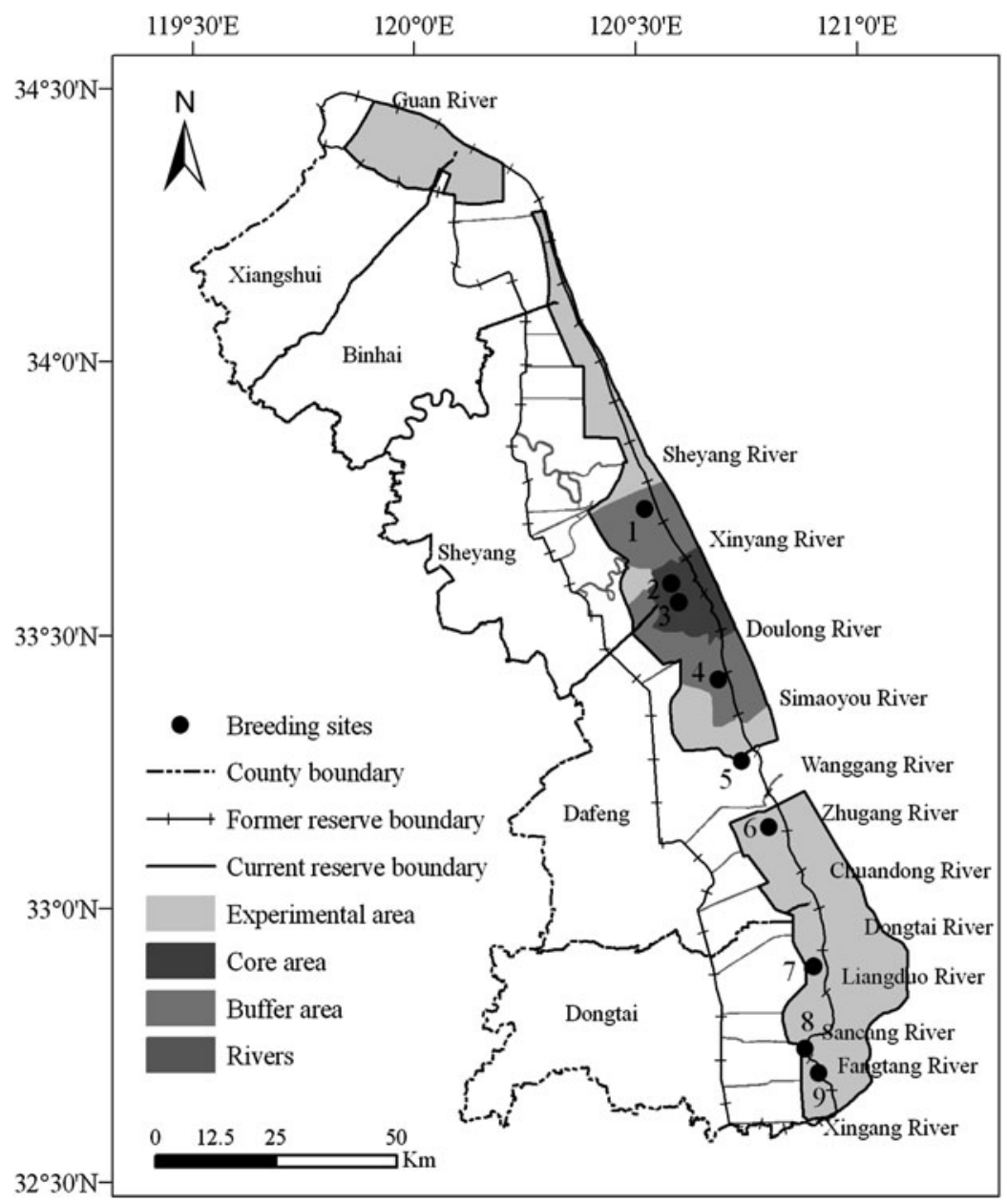

Figure 1. Nesting area distribution and revised functional areas of Yancheng NNR, Jiangsu Province. 1: Dongshagang, 2: North of core Area, 3: South of core area, 4: North of Simaoyou, 5: North of Wanggang, 6: North of Zhugang, 7: North of Liangduo River, 8: South of Sancang River, 9: South of Fangtang River.

\section{Processing of satellite imagery}

Cloud-free Landsat TM images for 1992, 1995, 1999, 2002, 2005 and 2007 were used for habitat classification (image orbits for each year include $120 / 36$ and 119/37), which were acquired from February to March since this is the dry season in the study area. Ancillary GIS data used in this research included a digital topographic map of Yancheng NNR from 1986 at the scale of 1:50,000.

All images were registered in a Gauss projection (identical to that of the topographic map) using ERDAS software. Between 50 and 60 ground control points (GCPs) were used for each image, which were evenly distributed throughout the whole study area. The registration procedure achieved an accuracy of less than 0.5 pixel rms error (RMSE) for images in 1992, 1995, 1999, 2002, 2005 and 2007.

Our study area runs across two TM images, so a mosaic was made in the pre-processing stage. We performed histogram matching between the adjacent images for the same year using ERDAS 
Imagine 8.7 software to conduct image-to-image radiometric normalisation, as suggested by Tang et al. (2005).

To establish visual interpretation marks, ground-truth surveys were conducted over the study area in order to collect real time ground-truth data between February and March in 2005 and 2007 with the help of a global positioning system (GPS). Reference data were collected extensively within the study area and vegetation cover was identified in the field. The accuracy of the resulting landscape maps was assessed using field survey reference data from the study area in 2005 and 2007. Their error matrix indicates that the overall accuracy exceeded $90 \%$.

\section{Classification of habitat types}

The sequence of the natural vegetation succession from the sea in a landward direction is: mudflats, Smooth Cordgrass, Common Seepweed, grassland and Common Reed Phragmites communis (Ma et al. 1999). We classified the coastal wetlands into 14 habitat types: residential area (RA), industrial land (IL), farmland (FL), forests (FR), reed (RD), grassland (GL), aquaculture ponds (AP), reservoirs (RE), salt pans (SP), rivers (RV), Common Seepweed (CS), Smooth Cordgrass (SC), mudflats (MF) and lower mudflats (LM). Meanwhile, we defined RD, $\mathrm{GL}, \mathrm{CS}, \mathrm{SC}, \mathrm{MF}$ and $\mathrm{LM}$ as natural wetlands, and $\mathrm{AP}, \mathrm{RE}, \mathrm{SP}$ and $\mathrm{FL}$ as anthropogenic wetlands.

\section{Data processing}

All vector data were converted to raster data on a $100 \mathrm{~m} \times 100 \mathrm{~m}$ grid scale. All spatial data were managed using ArcGIS 9.1. We used the Spatial Analyst tool to generate the habitat transition matrix between different years. The centroid coordinates of Common Seepweed and Smooth Cordgrass habitats were acquired using Mean Centre Function of Measuring Geographic Distributions in Spatial Statistics Tools, and the transition angle and distance were acquired by the Near Function analysis tools.

Using the point density function in Spatial Analyst, the annual nest density figure was generated and the number of nests in each cell was also obtained. We defined a minimum rectangle of 37,807 ha (the coordinates of the centroid are $\mathrm{N}_{33} 3.56329^{\circ}$ and $\mathrm{E}_{12} 2.58250^{\circ}$ ) to cover all nest-sites in the south of core area (site code 3 in Figure 1) during 1999-2007. The overall nest density figure was generated by adding the values of all rasters on a cell by cell basis. Proportions of abandoned nest-sites and available sites occupied between consecutive years (rates of nest-site turnover) were calculated for each nest area from nest-site turnover rate $=\left[0.5\left(\mathrm{~S}_{1} \div \mathrm{N}_{1}\right)+\left(\mathrm{S}_{2} \div\right.\right.$ $N_{2}$ )], where $S_{1}=$ number of sites occupied only the first year, $N_{1}=$ total number of sites occupied the first year, $\mathrm{S}_{2}=$ number of sites occupied only the second year, and $\mathrm{N}_{2}=$ total number of sites occupied the second year (Eileen 1996).

All statistics were preformed using SPSS 11.5 software. All means are presented \pm Standard Error (SE) with the range from minimum to maximum presented in brackets.

\section{Results}

\section{Population size and distribution of Saunders's Gull}

Annual mean population size and breeding population size were $994.09 \pm 170.17$ individuals $(n=11,575-1,300$ individuals $)$ and $874.09 \pm 189.49(n=11,575-1,300)$ separately across the eleven-year period (Table 1 ). Except in 2007 , the total population size was $>900$ individuals. The mean breeding population size in the core area of the reserve was $685.18 \pm 55.69$ individuals $(n=11,377-902)$, which accounted for $81.82 \% \pm 7.62 \%(36.82 \%-100 \%)$ of the total breeding population in 1992-2007. The number of breeding sites decreased from eight in 1992 and 1994 (Huang 1994, Wang and San 1994) to four in 1998 and a single site in 2000-2006 (Figure 2). Furthermore, in 2007, one new breeding site was observed. However, the total population size was only 575 gulls, which represented a decrease of about $45 \%$ in comparison with the earlier years. 
Table 1. Numbers and distribution of Saunders's Gull in coastal marshes of Yancheng NNR, 1992-2007.

\begin{tabular}{lrrlllllllr}
\hline Site code & \multicolumn{1}{c}{1} & \multicolumn{1}{c}{2} & 3 & 4 & 5 & 6 & 7 & 8 & 9 & \multicolumn{1}{c}{ Total } \\
\hline 1992 & 200 & 100 & 500 & 60 & 200 & 70 & 40 & 130 & & $1,300(1,300)$ \\
1994 & 340 & 80 & 377 & 34 & 55 & 54 & 16 & 68 & & $1,024(1,024)$ \\
1998 & 191 & 91 & 600 & & 38 & 30 & 28 & & & $979(920)$ \\
1999 & 168 & 86 & 592 & & 36 & 20 & 21 & & & $923(852)$ \\
2000 & 46 & 77 & 748 & & 71 & 24 & 24 & & 3 & $993(748)$ \\
2001 & 122 & 52 & 812 & & 54 & 20 & 8 & & 5 & $1,073(812)$ \\
2002 & 42 & 64 & 839 & & 32 & & 8 & & 6 & $991(839)$ \\
2003 & 30 & 59 & 862 & & 26 & & 4 & & 12 & $993(862)$ \\
2005 & 69 & 74 & 902 & & 22 & & & & 16 & $1,083(902)$ \\
2006 & 63 & 60 & 842 & & 12 & & & & 24 & $1,001(842)$ \\
2007 & 39 & 12 & 463 & & & & 10 & & 51 & $575(514)$ \\
\hline
\end{tabular}

Notes:Data from 1992, 1994 and 1998 were sourced from Huang (1994), Wang and San (1994) and Chu et al. (2000) respectively. The remaining data were collected during the field survey by the authors. The breeding population size is shown in parentheses. Site codes are as in Figure 1.

\section{Changes in land use and land cover}

The land cover classification clearly indicated that large areas of Common Seepweed have been lost along the beach from Sheyang River to Liangduo River except in the core of Yancheng NNR in the study area and that fragmentation of Common Seepweed habitats has occurred elsewhere. Calculations by each LULC class for 1992 and 2007 (Figure 3) showed that 79.1\% (27,358 ha) of Common Seepweed has been lost within this 15-year period, while the area occupied mainly by aquaculture ponds more than doubled (122.4\% increase) during the same period. However, the introduced Smooth Cordgrass habitat increased in area by 321.9\% (II,057 ha) from Sheyang River to Liangduo River from 1992 to 2007 (Figure 3). This mainly occupied the mudflats and constrained the natural transition of tidal vegetation, particularly the Common Seepweed community. The results also showed that land reclamation mostly occurred in Common Seepweed habitats in 1992-2002 and shifted to reclaim the Smooth Cordgrass habitats afterwards (Figure 3). The area of reed and mudflats decreased by $76.1 \%$ (30,686 ha) and $16.5 \%$ (15,810 ha) respectively, and that of farmlands increased by $12.0 \%(28,213$ ha) within this 15 -year period.

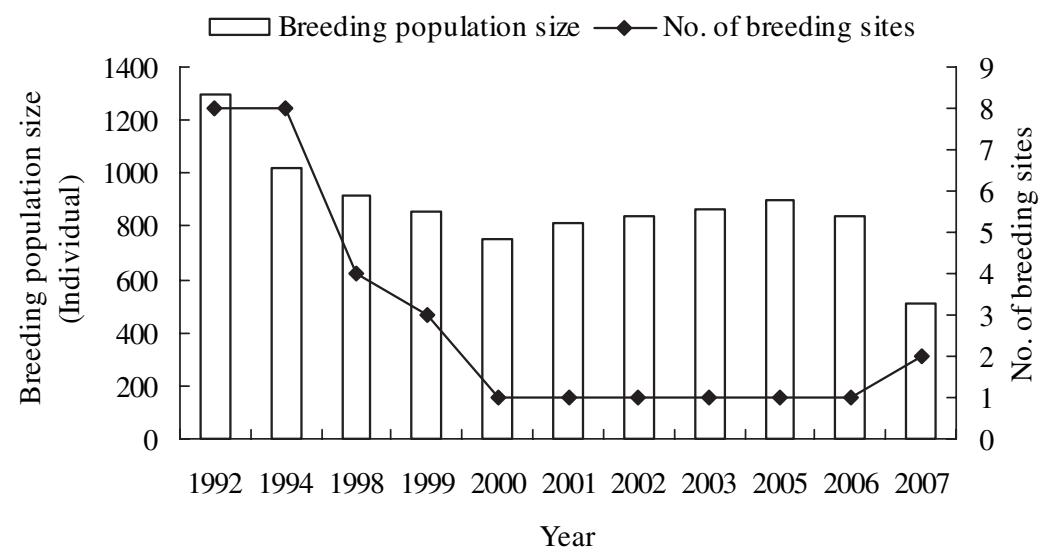

Figure 2. Changes in breeding population size and number of breeding sites of Saunders's Gull at Yancheng NNR 1992-2007. 


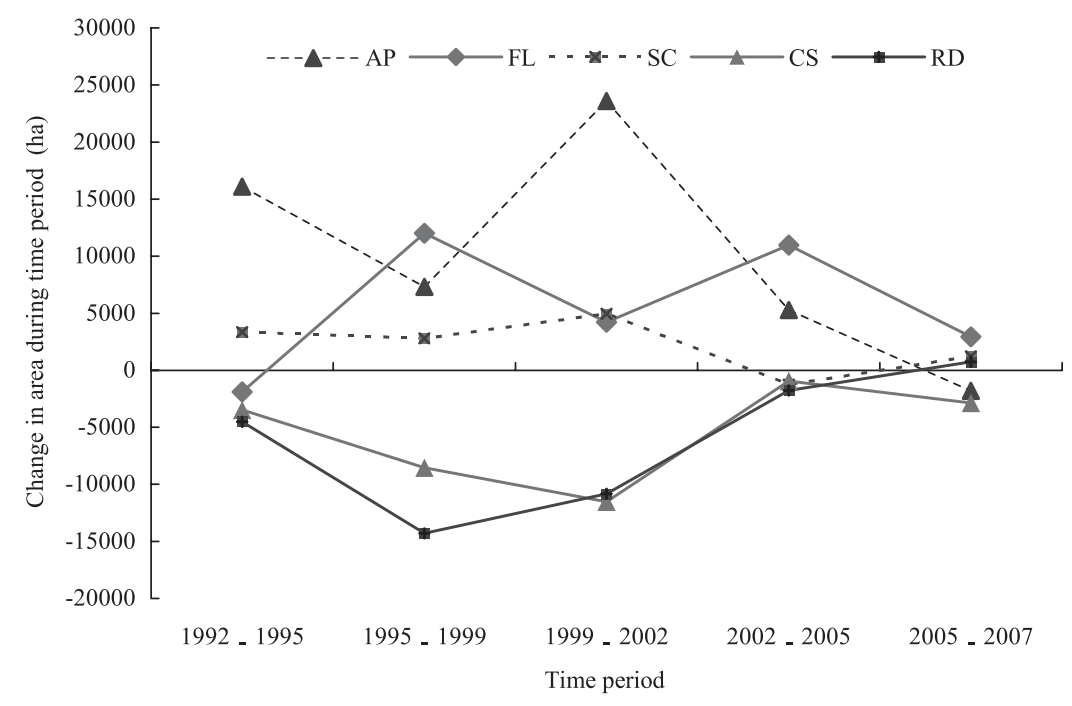

Figure 3. Changes between 1992 and 2007 in the area of five main types of land use or land cover in Yancheng coastal wetlands, Jiangsu (AP: Aquaculture ponds, FL: Farmland, SC: Smooth Cordgrass, CS: Common Seepweed, RD: Reed).

Land reclamation is the major cause of the loss of breeding habitats of Saunders's Gull. Seven breeding sites observed in 1992 and 1994 were lost due to land reclamation and were converted to aquaculture ponds, farmland and industrial use (Table 2).

\section{Changes in Common Seepweed and Smooth Cordgrass communities}

The number of patches (NP) and total area of the Common Seepweed community decreased continuously from 1992 to 2007 (Figure 4). However, the mean patch area did not change significantly $(P>0.05)$. This represented a decrease of $88.31 \%$, and conversion to aquaculture ponds was the main cause of Common Seepweed loss (Table 3). There was a significant difference in the area of this plant converted between 1992 and $2007\left(t_{4}=3.491, P<0.005\right)$, and its centroids shifted towards the south-east of the study area (Figure 5).

The NP of Smooth Cordgrass increased between 1992 and 1995, declined to 2002 and then increased in 2002-2007 (Figure 4). However, the area of Smooth Cordgrass increased significantly $(P<0.05)$. This represented an increase of $391.56 \%$, and $92.83 \%$ of the increased area was converted from the mudflats in this period (Table 3). The centroids of the Smooth Cordgrass community shifted towards the east (Figure 5).

Table 2. Date and causes of the loss of breeding sites of Saunders's Gull at Yancheng NNR (Site codes as in Fig. I).

\begin{tabular}{llll}
\hline Site code & Time & Area (ha) & Purpose of reclamation \\
\hline 1 & $1997-1999$ & 2,600 & Aquaculture ponds in Dongshagang \\
2 & $1997-1999$ & 1,400 & Convsersion to Phragmites in the north of core area \\
4 & $1994-1995$ & 1,442 & Aquaculture ponds in the north of Simaoyou \\
5 & $1996-1998$ & 1,685 & Storage base of Dafeng Port in the north of Wanggang \\
6 & $1998-2000$ & 3,033 & Aquaculture ponds between Wanggang and Zhugang. \\
7 & 1996 & 2,751 & Farmland in the north of Liangduo River. \\
8 & 1996 & 5,858 & Farmland between Liangduo River and Sancang River \\
\hline
\end{tabular}



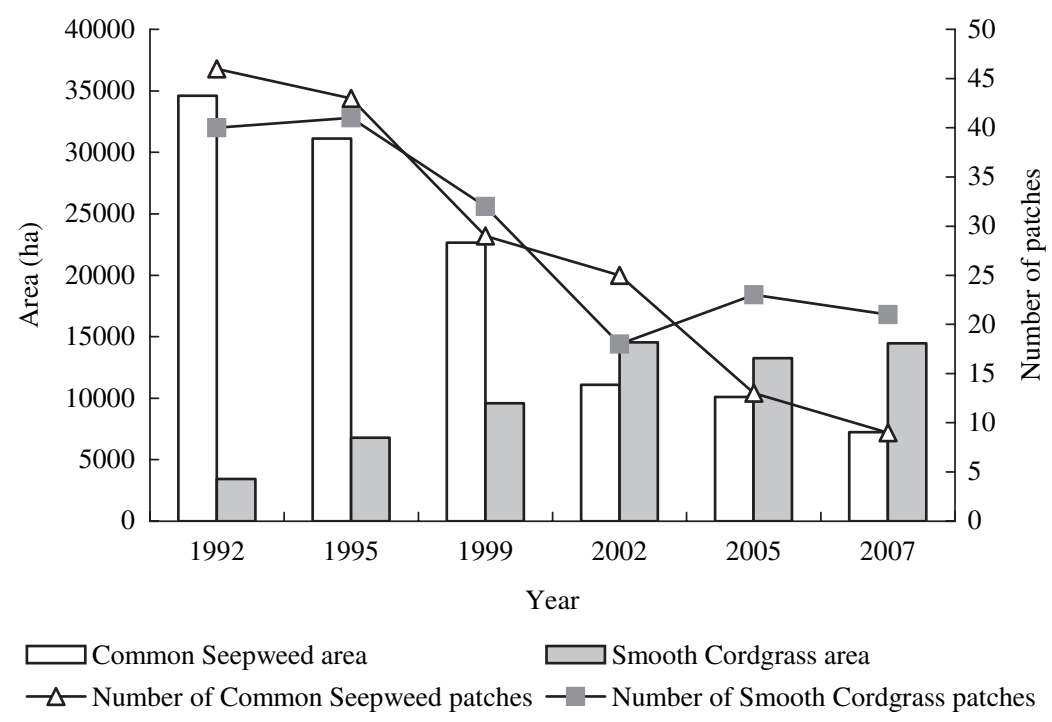

Figure 4. Area and number of patches of Common Seepweed and Smooth Cordgrass habitats in the study area 1992-2007.

\section{Number of nests and density of Saunder's Gull}

The number of nests in Zhonglugang tended to decrease and that of Sanlizha to increase (Table 4), with significant differences across years at Zhonglugang: $\left(t_{7}=6.29, P<0.01\right)$ and Sanlizha $\left(t_{7}=\right.$ $3.04, P<0.02)$, and differences within a year but between two sites $\left(t_{7}=3.537, P<0.01\right)$. The overall nest density map (Figure 6) indicated that 398 cells contained $1-2$ nests, 200 cells contained 3-8 nests and 20 cells contained 9-16 nests.

The overall mean turnover rate was $0.84 \pm 0.08(n=7)$, whereas in Zhonglugang it was $0.85 \pm 0.09(n=7)$ and in Sanlizha $0.79 \pm 0.18(n=5)$ (Table 5). The turnover rates of nest sites differed between years for Sanlizha $\left(t_{6}=24.936, P<0.01\right)$ and Zhonglugang $\left(t_{6}=\right.$ $3.612, P<0.02)$. However, the overall turnover rate did not differ between years $\left(t_{6}=1.695\right.$, $P>0.1)$.

\section{Discussion}

\section{Breeding habitat changes in Yancheng coastal wetlands}

Satellite images generally present the sole source of habitat data for many regions of the world important to wildlife (Gottschalk et al. 2005). The remote-sensing approach employed here to quantify changes in breeding habitats of Saunders's Gull indicates rapid and extensive declines in Common Seepweed with an annual loss in area of $5.27 \%$. The majority of these changes can be attributed to the widespread expansion of aquaculture within the area. The number of patches of Common Seepweed has declined significantly in the past 15 years and the expansion of Smooth Cordgrass is likely to further fragment the remaining habitat. These changes seriously threaten the distribution of breeding sites of the 'Vulnerable' Saunders's Gull.

The alien Smooth Cordgrass was introduced into Yancheng coastal wetland in 1982 (Zhong et al. 1985). This plant developed from scattered patches in estuarine regions into a continuous belt mainly distributed on the periphery of coastal wetlands from Sheyang River to Liangduo River from 1992 to 2007 (Liu et al. 2009a). Its spread has caused high levels of sediment accumulation, which constrains the natural transition of saline plants, especially Common Seepweed (Wang et al. 2006). Considering that Saunders's Gull prefers to nest in areas with 
Table 3. (a,b) The change in the area of (a) Common Seepweed and (b) Smooth Cordgrass habitats in Yancheng costal wetlands over five periods of varying length between 1992 and 2007. The extent of habitat loss or gain is expressed as the percentage change of the area at the beginning of each period.

\begin{tabular}{|c|c|c|c|c|c|}
\hline & \multicolumn{5}{|l|}{ Period } \\
\hline & $1992-1995$ & $1995-1999$ & 1999-2002 & $2002-2005$ & $2005-2007$ \\
\hline \multicolumn{6}{|l|}{ (a) Common Seepweed habitats } \\
\hline Initial area (ha) & 33,724 & 30,747 & 21,957 & 11,092 & 10,114 \\
\hline Loss to aquaculture (\%) & $9 \cdot 3$ & $23 \cdot 4$ & 48.6 & 8.9 & 22.3 \\
\hline Loss to other sources (\%) & 10.7 & 22.3 & 13.6 & 20.4 & 13.1 \\
\hline Total Loss (\%) & 20.0 & $45 \cdot 6$ & 62.2 & $29 \cdot 3$ & $35 \cdot 5$ \\
\hline Gain from mudflats (\%) & 6.1 & 6.6 & 9.5 & 16.2 & 6.2 \\
\hline Gain from other sources (\%) & 5.1 & 10.4 & $3 \cdot 3$ & $4 \cdot 2$ & 1.0 \\
\hline Total Gain (\%) & 11.1 & 17.0 & 12.8 & 20.5 & 7.2 \\
\hline Net change over period (\%) & -8.8 & -28.6 & $-49 \cdot 5$ & -8.8 & -28.3 \\
\hline \multicolumn{6}{|l|}{ (b) Smooth Cordgrass habitats } \\
\hline Initial area (ha) & 3,567 & 7,162 & 10,804 & 14,535 & 13,271 \\
\hline Loss to aquaculture (\%) & O.o & 3.6 & 31.7 & 36.2 & 16.9 \\
\hline Loss to other sources (\%) & 14.8 & $37 \cdot 9$ & 6.1 & 2.0 & 0.9 \\
\hline Total Loss (\%) & 14.8 & 41.4 & 37.8 & 38.2 & 17.8 \\
\hline Gain from mudflats (\%) & 85.5 & 72.0 & 53.6 & 20.9 & $23 \cdot 3$ \\
\hline Gain from other sources (\%) & 29.8 & $17 \cdot 9$ & 18.7 & 8.6 & $3 \cdot 5$ \\
\hline Total Gain (\%) & $115 \cdot 3$ & 89.9 & 72.3 & $29 \cdot 5$ & 26.8 \\
\hline Net change over period (\%) & 100.6 & 48.4 & $34 \cdot 5$ & -8.7 & 9.0 \\
\hline
\end{tabular}

coverage of $20 \%-60 \%$ of Common Seepweed (Jiang et al. 2002), breeding sites will disappear if no management measures are taken to prevent expansion of Smooth Cordgrass in the short-term.

Although this alien plant has expanded extensively in the study area, the coastal wetland from Liangduo River to Xingang River has not been occupied by this plant and the area of Common Seepweed habitat is still increasing. This area was occupied by Saunders's Gull in 2007 (site code 9 in Figure I) and is a potential breeding site for the gull if no land reclamation occurs in the future.

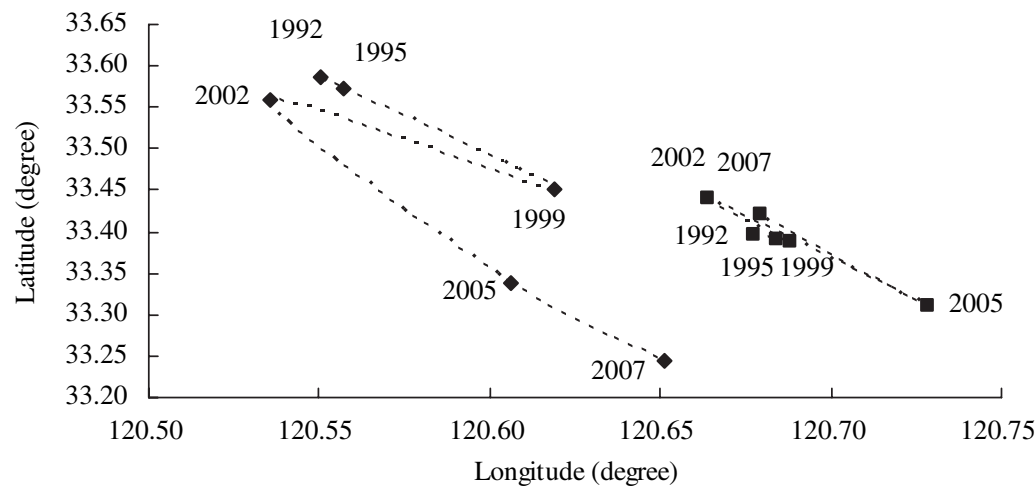

- - - - - Common Seepweed - - - - - Smooth Cord-grass

Figure 5. Mean centres of Common Seepweed and Smooth Cordgrass communities in Yancheng NNR 1992-2007. 
Table 4. The number and density of nests of Saunders's Gull in different nesting areas in the south of core area of Yancheng NNR, 1999-2007.

\begin{tabular}{llllllll}
\hline Year & \multirow{2}{*}{$\begin{array}{l}\text { Total No. } \\
\text { of nests }\end{array}$} & \multirow{2}{*}{$\begin{array}{l}\text { Nest density } \\
\text { per ha }\end{array}$} & \multicolumn{2}{l}{ Zhonglugang } & & \multicolumn{2}{l}{ Sanlizha } \\
& & & Nest no. & Nest density per ha & & Nest no. & Nest density per ha \\
\hline 1999 & 272 & 1.78 & 258 & 1.86 & 14 & 1.00 \\
2000 & 270 & 1.85 & 246 & 1.91 & 24 & 1.41 \\
2001 & 216 & 2.30 & 216 & 2.30 & 0 & 0.00 \\
2002 & 184 & 2.88 & 184 & 2.88 & 0 & 0.00 \\
2003 & 190 & 1.51 & 162 & 1.54 & 28 & 1.33 \\
2005 & 226 & 1.82 & 152 & 2.11 & 74 & 1.42 \\
2006 & 179 & 2.45 & 99 & 2.20 & 80 & 2.86 \\
2007 & 109 & 1.22 & 32 & 1.23 & 77 & 1.22 \\
\hline
\end{tabular}

\section{Threats to the Saunders's Gull population}

Saunders's Gull is dependent upon salt marshes and tidal mudflats, both for breeding and for its specialised diet, which mainly comprises crabs, but also includes small fish, shellfish and Common Clamworm Perinereis kinberg (Brazil and Melville 1991, Brazil 1992). The main threats to this species include habitat loss and degradation, invasion of Smooth Cordgrass, direct and indirect human disturbance and cumulative predation risk.

Using a non-dense dimidiate pixel model of remote-sensed normalized difference vegetation index (NDVI) data, Liu et al. (2009b) concluded the mean Common Seepweed coverage of nesting sites of Saunders's Gull was $34.98 \pm 6.8 \%$ based on 184 nests in 2002 and 109 nests in 2007. Due

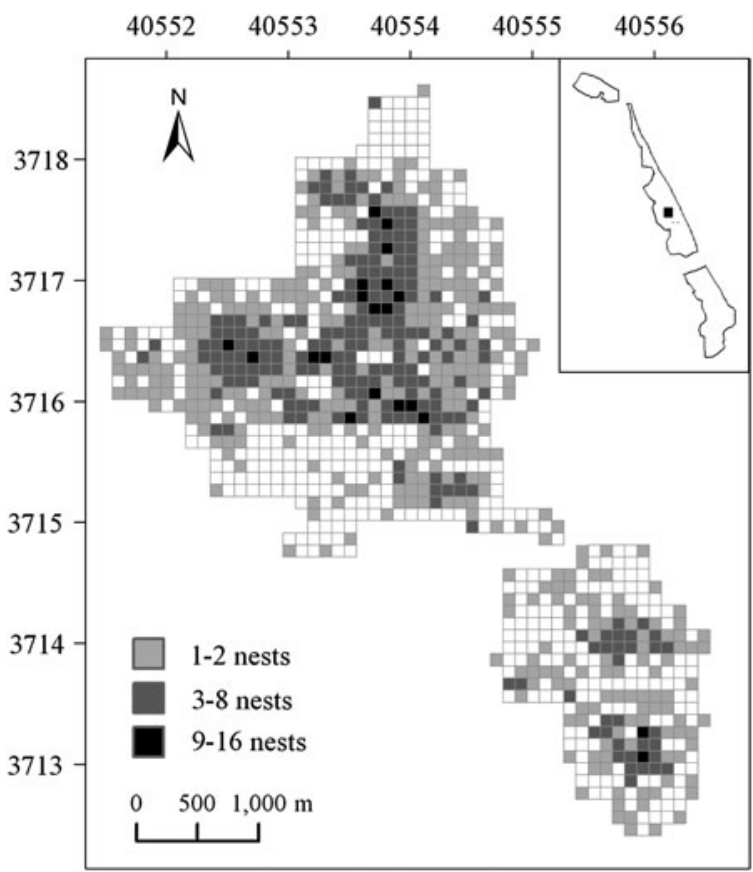

Figure 6. Nest-site density of Saunders's Gull in the south of core area of Yancheng NNR 1999-2007. 
Table 5. Turnover rates of nest-sites of Saunders's Gull in the south of core area of Yancheng NNR, 19992007.

\begin{tabular}{llllllll}
\hline Turnover rate & $1999-2000$ & $2000-2001$ & $2001-2002$ & $2002-2003$ & $2003-2005$ & 2005-2006 & 2006-2007 \\
\hline Overall & 0.78 & 0.81 & 1.00 & 0.82 & 0.89 & 0.81 & 0.77 \\
Zhonglugang & 0.78 & 0.80 & 1.00 & 0.81 & 0.93 & 0.75 & 0.88 \\
Sanlizha & 0.80 & $0.57^{*}$ & 0 & 0 & 1.00 & 0.92 & 0.64 \\
\hline
\end{tabular}

The asterisk indicates that the turnover rate is $2000-2003$ rather than $2000-2001$.

to the expansion of Smooth Cordgrass and a lack of regular seawater flushing in the core area of Yancheng NNR, the mean coverage of Common Seepweed habitats increased from $27.6 \pm 3.8 \%$ in 1992 to $35.4 \pm 2.0 \%$ in 2002 , and then to $53.1 \pm 4.5 \%$ in 2007 (Liu et al $2009 \mathrm{~b}$ ). In this case, the suitable nesting habitats for Saunders's Gull increased in 1992-2002, and then decreased 2002-2007.

In a stable and high quality breeding area, site fidelity can lead to higher reproductive success through the avoidance of predation and nest predation, improved feeding skills, and better adaptation to local circumstances in general (Vadász et al. 2008). Saunders's Gull appeared to have a very high spatial turnover of nesting sites in the core area of Yancheng NNR and presumably also low site tenacity of individuals, which indicates that the gull is probably susceptible to disturbance in the same way as Lesser Black-backed Gull Larus fuscus (Virkkala 2006).

Disturbance caused by human activities, such as collection of Common Seepweed, Common Clamworm and small crabs, has disrupted incubation and caused desertion of breeding sites. Other activities such as collection of Say's Paper-bubble Bullacta exarata, Onchidium struma and Lunatica gilva could disturb foraging birds and increase the risk of egg collection by local farmers. Meanwhile, fences for collection of small crabs will increase the risk of chicks falling into small jars placed along the fence (Jiang 2008). At present, the regulations in Yancheng NNR are lax and do not prevent continued building of new factories or restrict the increasing human activities.

\section{Concluding remarks}

Knowledge of population dynamics and habitat changes of Saunders's Gull can help development of management strategies for this 'Vulnerable' species. Preserving the breeding sites is a challenging task due to the species's spatio-temporal dynamics. New sites are continuously colonised and earlier inhabited sites become unoccupied. This is typical of colony-breeding gulls, such as Saunders's Gull, Black-headed Gull Larus ridibundus (Ulfvens 1993) and Lesser Blackbacked Gull (Virkkala 2006). Thus, it is recommended to conduct annual monitoring and to define a large enough range in one year to control disturbance to nesting, incubation and foraging, and increase breeding success.

In addition, habitat management is an important measure to prevent or reverse the direction of vegetation succession. Management of intertidal areas has also involved control of Common Reed and Smooth Cordgrass. It is recommended to use herbicide or mechanical disturbance to limit the expansion of Smooth Cordgrass, as has been applied in Europe to control Common Cordgrass Spartina anglica (Frid et al. 1999). In addition, artificial intervention or burning to create suitable vegetation cover of Common Seepweed is also a critical aspect of habitat manipulation to provide suitable nesting areas for gulls.

\section{Acknowledgements}

We thank Yancheng National Nature Reserve for giving us permission to conduct this study. In particular, we would like to thank Dr. Liu Chunyue, Institute of Northeast Geography and Agriculture Ecology of Chinese Academy of Sciences who provided technical support on image interpretation and data processing, and Mr. Sun Guorong, Liu Xiaoyun and Liu Sanzai who were involved in the field work for several years. We appreciate the Department of Wildlife Conservation, State Forestry Administration of China, for funding various aspects of this 
research. We are grateful to Mr. Crawford Prentice of the International Crane Foundation for the revision and useful comments on an earlier draft of this manuscript. Two anonymous referees made useful comments on a previous version of the manuscript.

\section{References}

BirdLife International (2008) The BirdLife checklist of the birds of the world, with conservation status and taxonomic sources. Version 1. Downloaded from http:// www.birdlife.org/datazone/species/downloads/BirdLife_Checklist_Version_ı.zip.

Brazil, M. A. and Melville, D. S. (1991) An immediate short-term management strategy for Saunders's Gull Larus saundersi. Hongkong: WWF.

Brazil, M. A. (1992) The threatened Saunders's Gull of east Asia. Birding World 5: 72-74.

Cao, L., Barter, M. A. and Wang, X. (2008) Saunders's Gull: A new population estimate. Bird Conserv. Internatn. 18: 301-306.

Chu, G. Z., Hou, Y. Q., Qian, F. W., Liu, X. P. and Wang, H. (2000) The population and distribution of several waterbird species around the coast of Yancheng, Jiangsu Province in breeding season. Sci. Silvae Sin. 36: 87-92.

$\mathrm{Du}$, J. J. (1994) Study on the breeding ecology of Saunders's Gull. Chi. J. Zool. 29: 32-34.

Eileen, M. K. (1996) Habitat selection and productivity of Least Terns on the lower Platte River, Nebraska. Wildl. Monogr. 132: 1-48.

Frid, C. L. J., Chandrasekara, W. U. and Davey, P. (1999) The restoration of mudflats invaded by common cordgrass (Spartina anglica, CE Hubbard) using mechanical disturbance and its effects on the macrobenthic fauna. Aquat Conserv. 9: 47-61.

Gottschalk, T. K., Huettmann, F. and Ehlers, M. (2005) Thirty years of analysing and modeling avian habitat relationships using satellite imagery data: a review. Int. J. Remote Sens. 26: 2631-2656.

Han, N. Y. and Gretchen, J. de B. (1995) China's Biosphere Reserves. Beijing: Chinese National Committee for MAB.

Hou, Y. Q., Chu, G. Z., Qian, F. W., Lu, J. and Dai, M.. (2000) The population and distribution of Saunders's Gull Larus saundersi along the eastern coastline of China. Pp.
214-218 in Studies on Chinese ornithology. Proceedings of the $4^{\text {th }}$ Ornithological Symposium of Mainland \& Taiwan, China). Beijing: China Forestry Publishing House.

Huang, Q. A. (1994) Status and distribution of Saunders's Gull Larus saundersi. Pp. 24-29 in Waterbirds research in China. Shanghai: East China Normal University Press.

IUCN (2008) 2008 IUCN Red List of threatened species. <www.iucnredlist.org>. Downloaded on 1o March 2009.

Jiang, H. X., Chu, G. Z., Qian, F. W. and Lu, J. (2002) Breeding microhabitat selection of Saunders's Gull (Larus saundersi) in Yancheng of Jiangsu Province, China. Biodiv. Sci. 10: 170-174.

Jiang, H. X. (2008) Breeding ecology, population status and conservation strategies. Ph.D Dissertation. Beijing Normal University.

Liu, C. Y., Zhang, S. Q., Jiang, H. X. and Wang, H. (2009a) Spatiotemporal dynamics and landscape pattern of alien species Spartina alterniflora in Yancheng coastal wetlands of Jiangsu Province, China. Chi. J. Appl. Ecol. 20: 901-908.

Liu, C. Y., Zhang, S. Q., Jiang, H. X., Li, X. F., $\mathrm{Na}, \mathrm{X}$. D. and Wen, Z. F. (2009b). Remote sensing monitoring on dynamics of nesting habitats of Saunders's Gull Larus saundersi. Acta Ecol. Sin. 29(8): 4285-4294.

Ma, Z. J., Wang, Z. J. and Tang, H. X. (1999) Habitat use and selection by Red-crowned crane (Grus japonensis) in winter in Yancheng Biosphere Reserve, China. Ibis 141: 135-139.

Melville, D. S. (1987) Saunders's Gull Larus saundersi. Paper presented at International Crane Workshop, Qiqihar, People's Republic of China, May 1-10 1987.

Moores, N. (2002) Wetlands: Korea's most threatened habitat. Oriental Bird Club Bull. 36: 54-60.

Nanjing Environment Sciences Institute of the State Environment Protection Agency of China, Nanjing Normal University and 
Management Bureau of Yancheng National Nature Reserve (2005) Master Plan of Yancheng National Nature Reserve.

Shi, Z. R., Thouless, C. R. and Melville, D. S. (1988) Discovery of the breeding grounds of Saunders's Gull Larus saundersi. Ibis 130: $445-446$.

Swinhoe, R. (1871) On a new Chinese gull. Proc. Zool. Soc. Lond. 1871: 273-275.

Tang, J. M., Wang, L. and Zhang, S. W. (2005). Investigating landscape pattern and its dynamics in 1999-2000 of Daqing, China using remote sensing and GIS. Intl. J. Remote Sensing 26: 2259-2280.

Ulfvens, J. (1993) Population and colony site dynamics in black-headed gulls Larus ridibundus breeding on the Finnish west coast. Ornis Fennica 70: 96-101.

Vadász, C., Német, Á., Karcza, Z., Loránt, M., Biró, C. and Csörgö, T. (2008) Study on breeding site fidelity of Acrocephalus warblers in central Hungary. Acta Zool. Hung. 54: 167-175.

Virkkala, R. (2006) Spatiotemporal variation of breeding gull species in a boreal lake complex in Finland: implications for conservation. Biol. Conserv. 128: 447454 .

Wang, A. J., Gao, S. and Jia, J. J. (2006) Impact of Spartina alterniflora on sedimentary and morphological evolution of tidal salt marshes of Jiangsu, China. Acta Oceanol. Sin. 28: 92-99.

Wang, H. and San, D. J. (1994) The status of Saunders's Gull on the east coast of China. Pp. 245-249 in Management plan for Saunders' Gull Larus saundersi. Hong Kong: WWF Project CNoo32.01.

Wetlands International. (2006) Waterbird population estimates - Fourth edition. Wageningen, The Netherlands: Wetlands International.

Zheng, G. M. and Wang, Q. S. (1998) China red data book of endangered animals (Aves). Beijing: Science Press.

Zhong, C. X., Zhou, R. Z., Zhou, H. B. et al. (1985) Study on the introduction and cultivation of Spartina alterniflora and its effects of saline soil amelioration in China. J. Nanjing Univ. 40: 42-28.

\section{H. X. JIANG}

Key Laboratory of Forestry Protection of State Forestry Administration; Institute of Forest Ecology, Environment and Protection, Chinese Academy of Forestry, Beijing, 10oog1, China and Ministry of Education Key Laboratory for Biodiversity Science and Ecological Engineering; College of Life Sciences, Beijing Normal University, Beijing, 100875, China.

Y. Q. HOU, G. Z. CHU, F. W. QIAN, G. G. ZHANG

Key Laboratory of Forestry Protection of State Forestry Administration; Institute of Forest Ecology, Environment and Protection, Chinese Academy of Forestry, Beijing, 10oog1, China.

H. WANG

Yancheng National Nature Reserve, Xinyanggang Town, Sheyang County, Yancheng City, Jiangsu Province, 224002, China.

G. M. ZHENG*

Ministry of Education Key Laboratory for Biodiversity Science and Ecological Engineering; College of Life Sciences, Beijing Normal University, Beijing, 100875, China.

${ }^{*}$ Author for correspondence; e-mail: zhenggm@bnu.edu.cn

Received 14 September 2008; revision accepted 15 June 2009;

Published online 27 January 2010 